\title{
Guiné-Bissau e Brasil: Minhas margens do Atlântico
}

\author{
Jorge Otinta ${ }^{1}$
}

Tenho a impressão de que escrever este pequeno diário acadêmico para os leitores da Revista Crioula é um desafio e tanto. Mas, apesar disso, tentarei esboçar alguns eventos relevantes neste percurso rumo à minha pós-graduação em Estudos Comparados na Universidade de São Paulo; percurso que começa, na verdade, a partir de 2002, quando já estava de volta a Guiné-Bissau depois de um período de quatro anos morando em São Paulo a estudos.

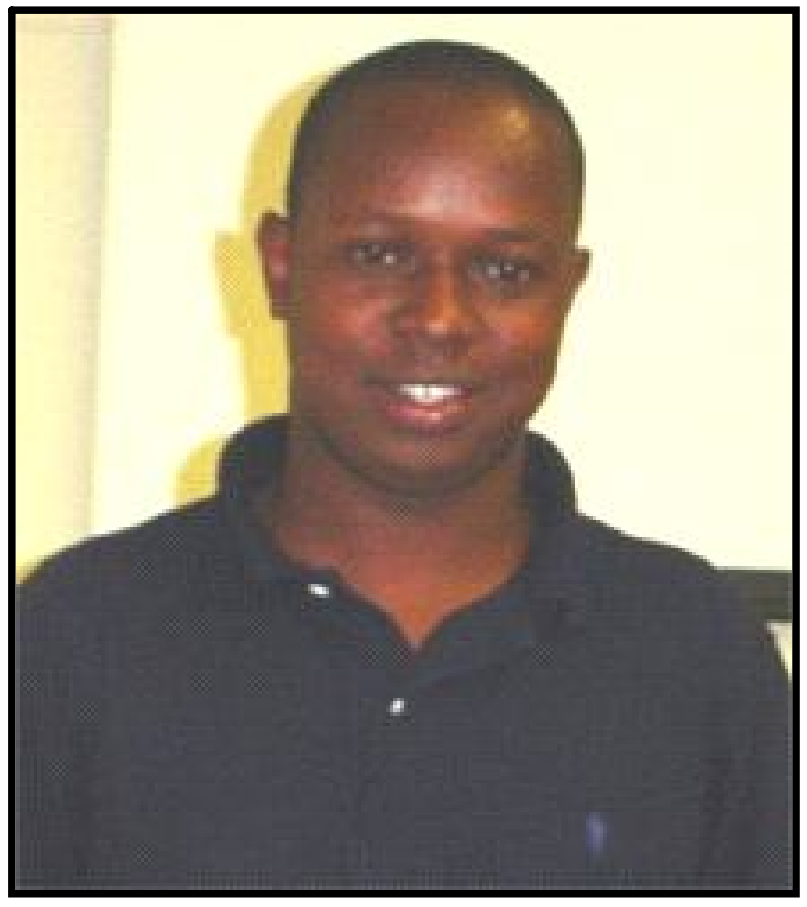

Sempre tive uma certa paixão pelo Brasil, ainda a mantenho, e pelos brasileiros; por sua cultura e modo alegre de viver. Esta é a razão de ter escolhido o Brasil e não Portugal, por exemplo, ou outro país que fosse. Por gosto. A minha família nunca viajou e, talvez por isso tenha apoiado a minha decisão de viajar por este mundo afora em busca de novos espaços ao sol neste imenso mundo em que vivemos. Uma busca prenhe de paixão, coragem mas também de medos. De medos que, as vezes, desencorajam; mas como as forças eram bem maiores que o medo, digo, com segurança, combati um bom combate.

\footnotetext{
1 Mestrando em Estudos Comparados de Literaturas de Língua Portuguesa. FFLCH/USP (PEC-PG).
} 


\section{Idas e vindas}

Voltei para Bissau após a graduação para adquirir experiência profissional na minha área de formação: Letras, com licenciatura em Português e bacharel em tradução pela PUC/SP, em 2001. Aliás, foi na PUC que mantive os primeiros contatos com as obras do brasileiro Milton Hatoum, nomeadamente, Relato de um certo Oriente e Dois Irmãos. Fascinado pelas duas obras, decidi, um dia, estudar uma delas. Já em Bissau, conheci a obra de Mia Couto, isto em 2002. A partir da leitura de suas obras como O Último Vôo do Flamingo, A Varanda do Frangipani, Um rio chamado tempo, uma casa chamada terra, entre outras, decidi, então, trabalhar com os dois autores, na tentativa de aproximar e de diferenciá-los, no contexto das literaturas produzidas em língua portuguesa, mais especificamente, nas questões relativas às identidades e memória em Relato de um certo Oriente e Um rio chamado tempo, uma casa chamada terra. Embora, com o tempo, isto e, a medida que fui avançando na minha pesquisa, fui deixando Milton Hatoum de lado. Foi uma escolha dura de fazer; mas nao tive outro jeito. Fui ficando cada vez com a obra de Mia Couto. Pena!!!

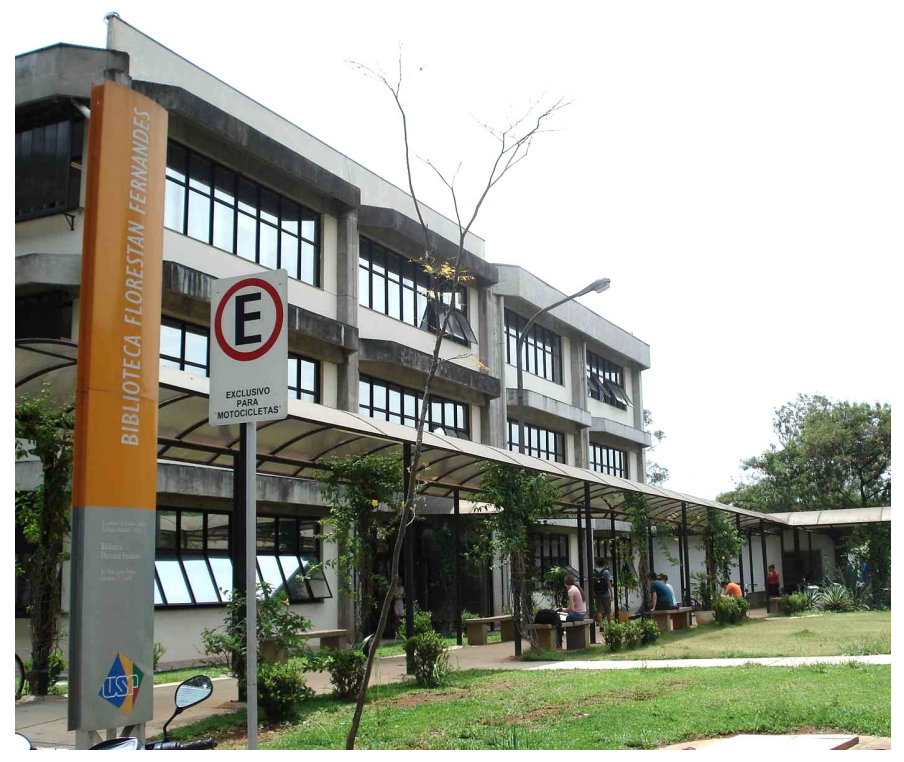

Biblioteca da FFLCH - USP
Escolhi a USP pela excelência acadêmica, mas principalmente, porque nela eu teria condições de desenvolver a minha pesquisa na área das Literaturas Africanas, com renomados professores. A professora Rita Chaves foi especialmente indicada por uma exaluna da área de literatura brasileira que fez algumas 
matérias da área de Estudos Comparados, na altura, minha colega na PUC/SP.

Encetei o diálogo com a professora Rita sobre o meu projeto por dois anos, isto é, de 2003 a 2004, através de e-mails e conversas construtivas, pela Internet. Foram muitos e-mails até que o meu projeto "original" intitulado Memória e Identidade em Um rio chamado tempo, uma casa chamada de terra, de Mia Couto e Relato de um certo Oriente, de Milton Hatoum pudesse ser aceito pela professora. Assim, em Maio de 2004, recebo em Bissau a Carta de Aceitação dela e a da faculdade.

\section{Sobre a pesquisa}

Diferentemente do moçambicano Mia Couto, já conhecido e prestigiado, Milton Hatoum é praticamente desconhecido na GuinéBissau. A opção por um autor moçambicano em vez de um guineense para um estudo comparativo deu-se em função da pouca produção em prosa no meu país, além do fato de o tema que eu queria estudar (Memória e Identidades) ser tratado por poucos autores guineenses, como Abdulai Sila e Filinto Barros, por exemplo. Ou pelo menos o tema não é tratado, em termos de profundidade, tanto quanto o fazem Milton Hatoum e Mia Couto.

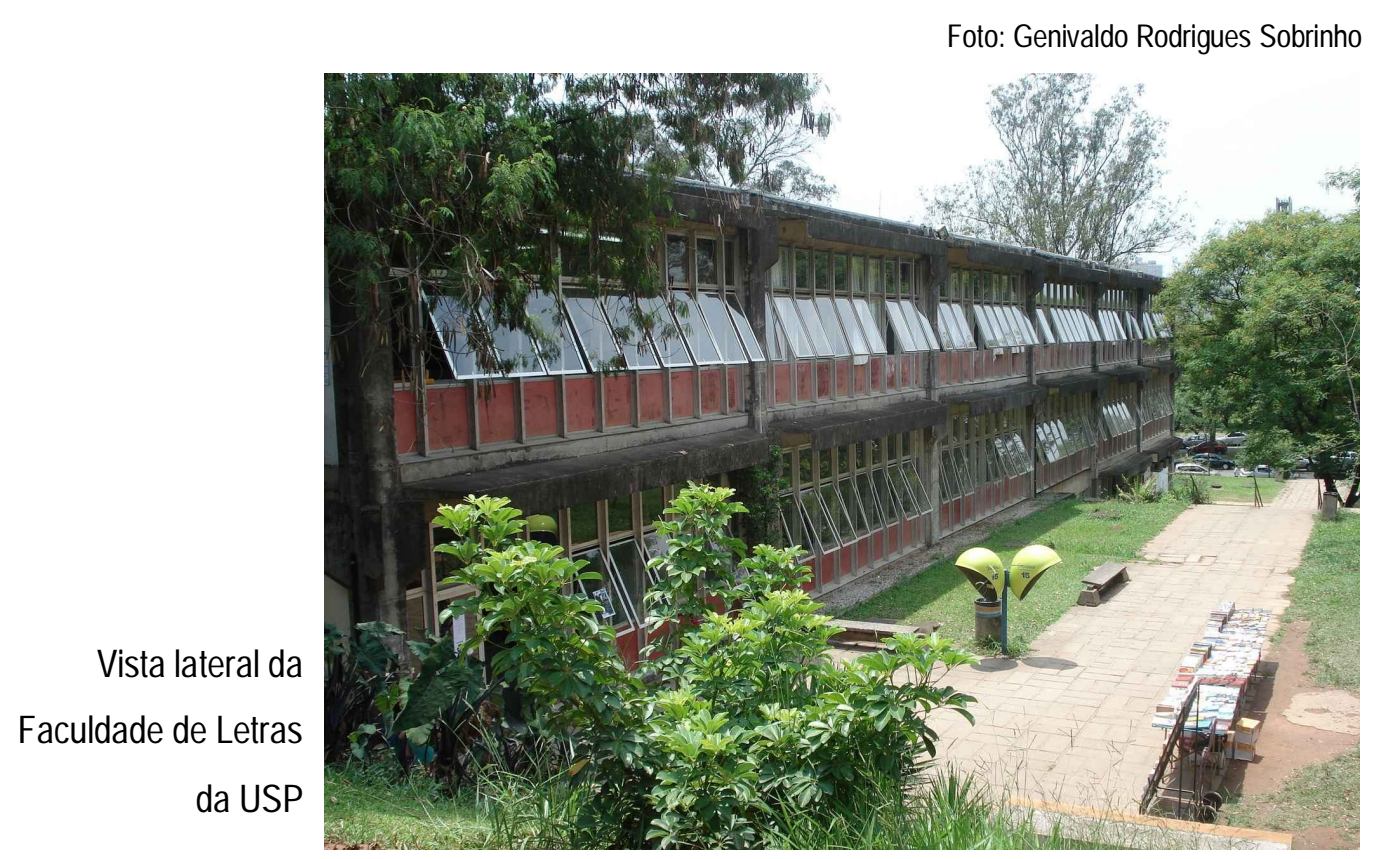




\section{O intercâmbio}

Minha vinda para a pós-graduação na USP se deu através do PEC, por intercâmbio. PEC significa Programa de Estudante Convênio. Existem dois: PEC-G e PEC-PG, da graduação e pós-graduação, respectivamente. É resultado de acordo cultural-educacional entre o Brasil e os paises africanos e hispano-americanos. A cada ciclo (graduação e pós-graduação [mestrado e doutorado]) concluído no Brasil por estes alunos, eles devem retornar ao país de origem para trabalharem por dois anos, somente após esse período eles podem pleitear um novo ciclo acadêmico. Na graduação, por exemplo, existem dois modelos: um é o da bolsa de estudos financiada pelo governo brasileiro, via Itamaraty; outro é o da bolsa financiada pelos governos dos países de origem do estudante. A seleção e feita nas representações diplomáticas brasileiras no país de origem do estudante. Na pósgraduação são o CNPq e a CAPES que financiam os projetos de estudos mediante a aprovação do Programa e da Faculdade.

\section{Enfim, nas salas de aulas}

Em março de 2005 chego a São Paulo para dar início aos meus estudos. Este ano foi intenso tanto em termos de aulas ministradas pelos meus professores Benjamin Abdala Jr. no curso de "Comparatismo Literário em Língua Portuguesa”, e Rita Chaves, com “Temas e Tópico das Literaturas Africanas de Língua Portuguesa”, como pela convivência com colegas da área. Foi genial. No $2^{\circ}$ semestre tive mais uma aula com o Prof. Benjamin sobre "Clássicos das Literaturas e Cultura dos Países de Língua Portuguesa”. Um curso profundo e esclarecedor. E as aulas como sempre, estupendas!

No $1^{\circ}$ semestre de 2006 tive mais dois cursos lindos com as professoras Tânia Macedo da área de Estudos Comparados e Andréa Hossne da área de Teoria Literária e Literatura Comparada, "Uma cidade e suas leituras nas Literaturas Africanas de Língua Portuguesa” 
e "Formas e Tendências na Narrativa Contemporânea", respectivamente.

Confirmei a forte vocação da USP para pesquisa, pesquisa e muita pesquisa. As aulas não são "dadas", elas são feitas, com a participação de alunos e professores. Na PUC/SP, por exemplo, há pesquisa sim, mas as aulas, segundo me pareciam, nos idos anos de 1998-2001, são dadas, como o são as grandes aulas magnas.

Não posso deixar de mencionar a ótima Biblioteca e estrutura geral da FFLCH (Faculdade de Filosofia, Letras e Ciências Humanas).

Foto do autor

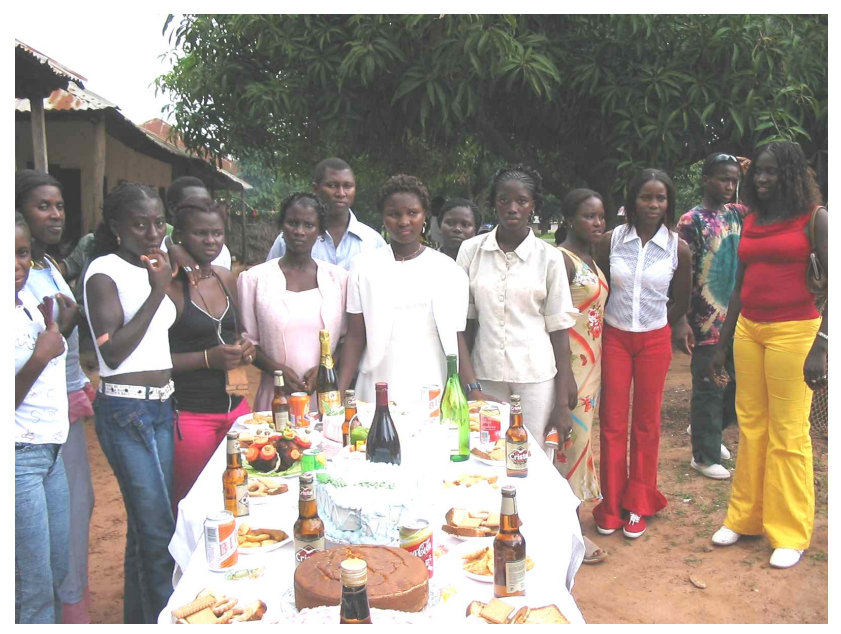

Copo d'agua: a festa de batizado (Bissau)

\section{Uma grande familia acadêmica}

$\mathrm{Na}$ USP, como um todo, encontrei, sem surpresas, um ambiente acadêmico favorável ao crescimento e a um bom nível de relacionamento profissional, quiçá mesmo pessoal, com todos os que estão a minha volta: professores e colegas alunos brasileiros, de países africanos e sul-americanos.

Uma pergunta que me fazem é se estranhei a marcante ausência de alunos brasileiros negros na USP. Respondo que não sei se a palavra certa é estranhar. Mas que espero que os negros brasileiros tentem, por iniciativa própria, criar condições que os ajudem a marcar mais presença na universidade, pressionando, é claro, governos municipais, estaduais e federal neste sentido. A palavra é lutar por um lugar ao sol, participar desta grande família acadêmica.

\section{Um gigante chamado cidade}

São Paulo sempre foi o que eu já imaginava antes de aqui chegar: um gigante chamado cidade. Gosto, por incrível que pareça, de cidades- 
malucas, como me parece ser a São Paulo. À primeira vista, estranhei a presença-correria de sua gente, parecia gente a correr da morte; só depois, fui descobrindo, aos poucos, que estavam (estas pessoas) a correr atrás do pão nosso de cada dia. Prontos, como diz o vulgo, saco vazio não para em pé. Mas São Paulo e fantástica, apesar desta correria. E que maravilha de cidade!

Também recomendo a outros estudantes de meu país a virem viver esta experiência de intercâmbio, que vale a pena e muito. Pelo crescimento acadêmico, pela experiência de vida, pela maneira de lidar com as saudades.

As saudades em mim são como aquelas cicatrizes que uma vez havidas no nosso corpo para sempre estarão presentes nele; quer recordemos, quer não recordemos delas. Sinto falta da minha família, dos meus amigos e parentes. Mas é assim a vida. Se tivéssemos tido uma universidade na Guiné talvez a história tivesse sido outra. Ou seja, se tivéssemos universidade nos idos anos 80/90. Bem, só recentemente, isto e, em 2003/04, foram criadas duas universidades, a Universidade Amílcar Cabral, publica e a Universidade Colinas de Boe, privada.

Acho também que seria bom, quando houver oportunidade de intercâmbio, que os estudantes brasileiros vão e conheçam a GuinéBissau por dentro; enfim, esta parte de África encostada ao Atlântico. Conviver com a hospitalidade deste povo maravilhoso; nisso, na hospitalidade, somos iguais.

\section{A reta final e o futuro}

O meu futuro é o momento. Por isso, neste momento em que estou a ultimar a minha dissertação, já estou com um projeto quase pronto, voltar a cursar Direito, curso que tive que abandonar no $2^{\circ}$. Ano em 1998 para vir cursar Letras. 
Bem, em síntese, é este o meu percurso acadêmico na USP. Espero ainda terminar meu mestrado até o final deste ano. Se o conseguir terei cumprido mais um grande objetivo.

Um abraço e minhas manteñas (saudações) a todos.

São Paulo, Outubro de 2007.

Foto: Genivaldo Rodrigues Sobrinho

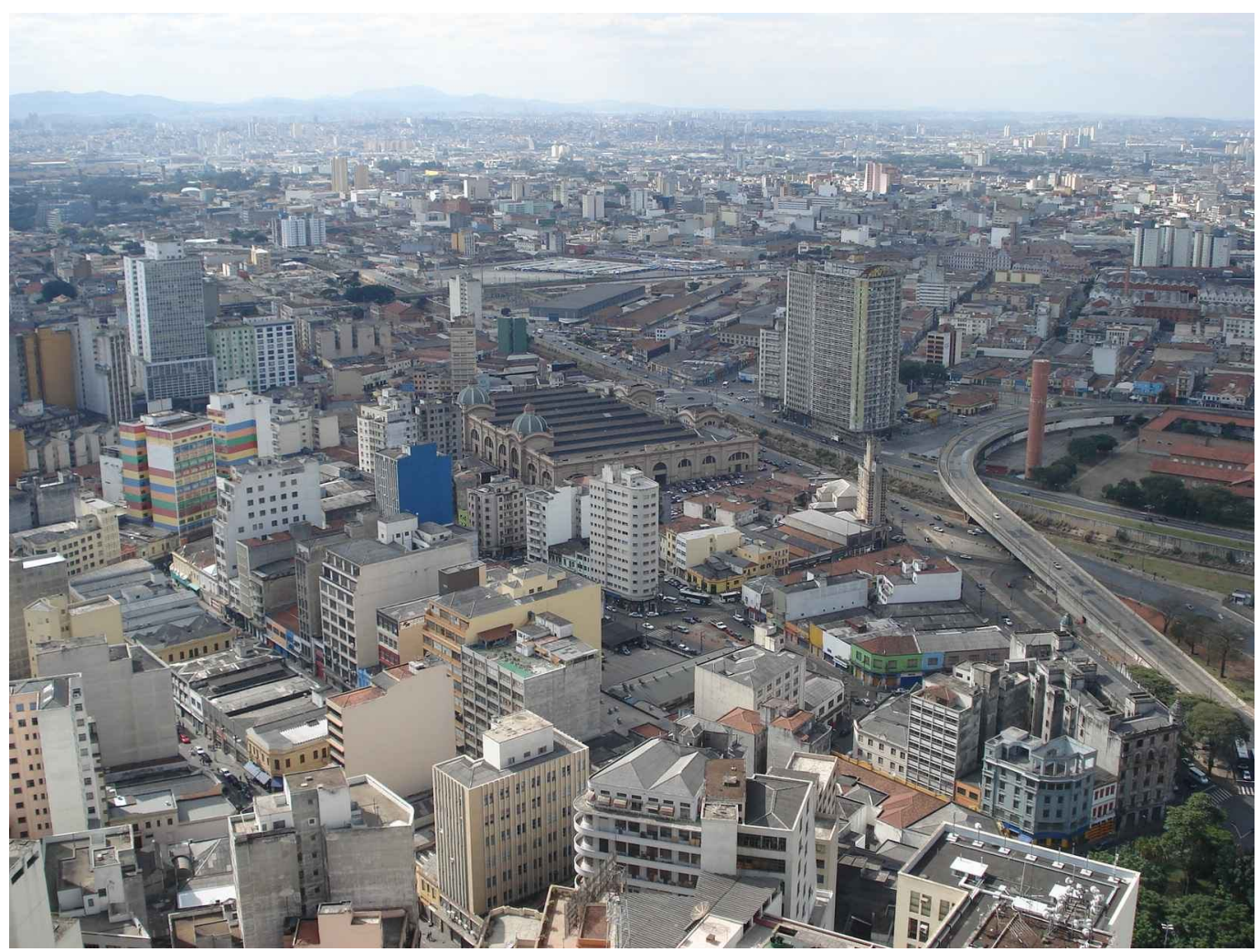

Vista do centro da cidade de São Paulo 